\title{
Scorpionic Serotherapy in pregnancy and its effects on the offspring
}

Paz G.G ${ }^{1,2}$; Nencioni A.L.A. ${ }^{1}$; Paulo M.E.V ${ }^{1}$

${ }^{1}$ Laboratory of Pharmacology, Butantan Institute, São Paulo, Brazil

2Pos Graduation Program on Toxinology, Butantan Institute, São Paulo, Brazil

\section{Introduction and aims}

It is known that scorpion venom can cause problems ranging from simple local manifestations, such as small edema, to serious problems, such as cardiocirculatory complications, which can lead to death. In the case of an accident during pregnancy, there are risks for both the mother and the fetus, causing the death of both in extreme cases. Serotherapy is the most suitable method for treating scorpion envenoming. However, there are very few studies regarding the effects of the antivenom on the fetus, whether beneficial or not. Therefore, this project aims to study and elucidate the effects of perinatal scorpion serotherapy, checking if there is any physiological change in the fetus, as well as if there is a reversal of the changes caused by the envenoming of their mothers.

\section{Methods}

- Pregnant rats were separated into four groups:

Gestational day 2 (GD2)

\begin{tabular}{|c|}
\hline $\begin{array}{l}\text { Control group }(\mathrm{n}=10) \\
\text { Saline }(1 \mathrm{ml} / \mathrm{kg}) \text { s.c. } \\
45 \mathrm{~min} \\
\text { 2x Saline }(0.2 \mathrm{ml}) \text { i.v. }\end{array}$ \\
\hline $\begin{array}{l}\text { Venom group }(n=10) \\
\text { Venom }(4 \mathrm{mg} / \mathrm{kg}) \text { s.c. } \\
45 \mathrm{~min} \\
\text { 2x Saline }(0.2 \mathrm{ml}) \text { i.v. }\end{array}$ \\
\hline $\begin{array}{l}\text { Antivenom group }(\mathrm{n}=10) \\
\text { Saline }(1 \mathrm{ml} / \mathrm{kg}) \text { s.c. } \\
45 \mathrm{~min} \\
\text { 2x Antivenom }(0.2 \mathrm{ml}) \text { i.v. }\end{array}$ \\
\hline $\begin{array}{l}\text { Venom/antivenom group }(\mathrm{n}=10) \\
\text { Venom }(4 \mathrm{mg} / \mathrm{kg}) \text { s.c. } \\
45 \mathrm{~min} \\
\text { 2x Antivenom }(0.2 \mathrm{ml}) \text { i.v. }\end{array}$ \\
\hline
\end{tabular}

- The weights and food and water intake of mothers were measured at 0,5 th, 10th, 16th and 21st gestational days to assess the maternal toxicity;

- At 21st gestational day, each pregnant rat were euthanized and laparotomized, and their uterus weighted;

- Each puppy were weighted alongside it's placenta, and divided into two groups:

\begin{tabular}{|l|}
\hline Visceral analysis \\
Puppies were submerged in Bouin's \\
solution for four days and then \\
submerged in alcohol. Using Wilson's \\
method (1965), each puppy were cut \\
into specific sections in order to \\
visualize visceral anomalies or \\
malformations
\end{tabular}

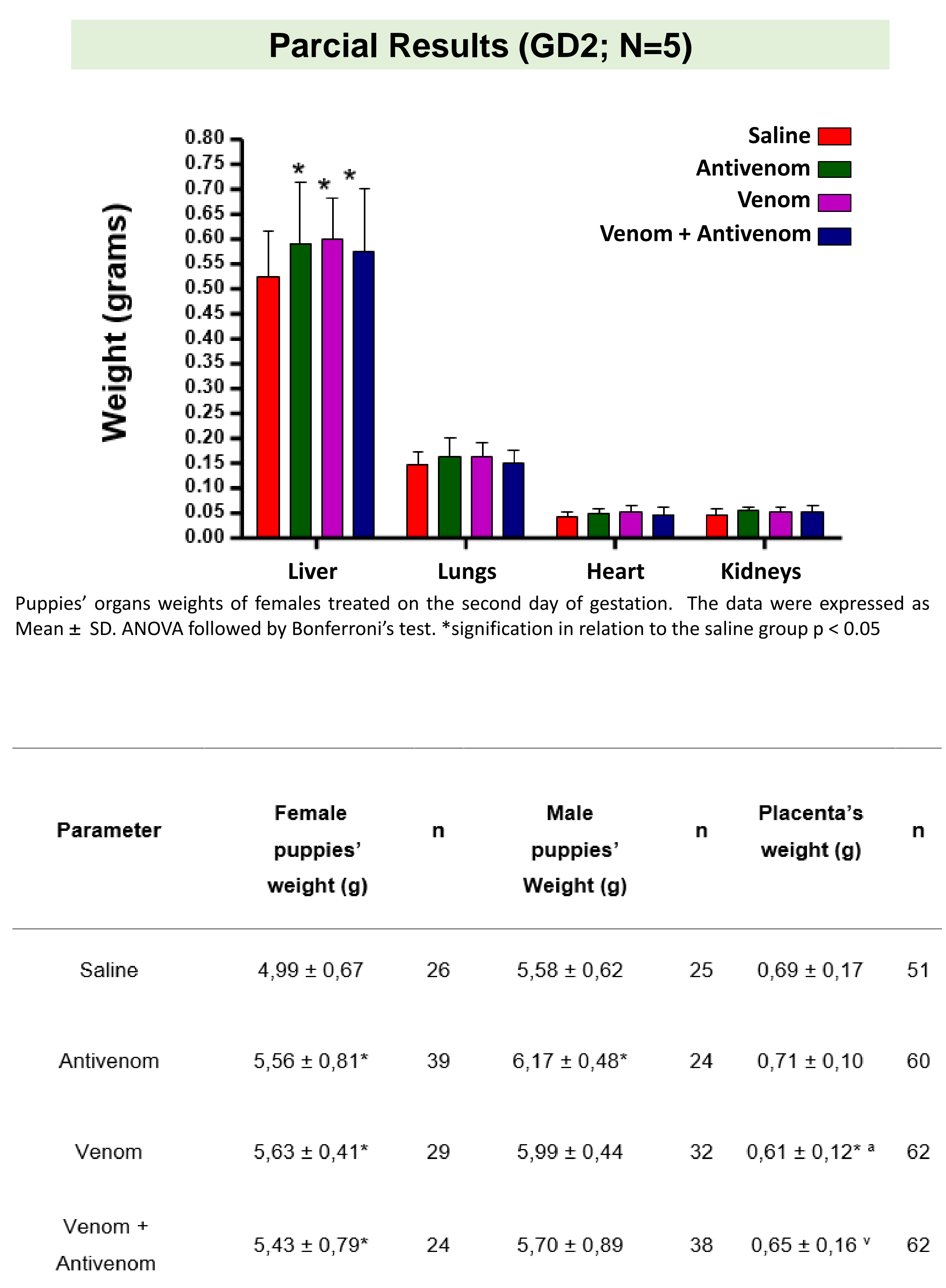

The data were expressed as mean SD.ANOVA followed by Dunn's test. *: Significance in relation to the saline group; a: Significance in reletion to the antivenom group; $v$ : Significance in relation to the venom group $p<$ 0.05

\section{Conclusion}

The current preliminar study showed that the antivenom can cause changes in the offspring when injected on their mother at GD 2. Further studies with a greater $\mathrm{N}$ are being conducted in order to see if the significance still holds. Another study are being conducted with different treatment day (GD 10), in order to see if the antivenom can cause different changes at different days that are important to the gestational progress. 